\title{
The Impact of WhatsApp on the Blood Donation Process in Saudi Arabia
}

\author{
Qarmoosha Rasheed Al-Hajri' \\ Asma Alfayez $\mathbb{D D}^{\prime}$ \\ Demah Alsalman (D) \\ Fahad Alanezi $\left.{ }^{2}\right)^{2}$ \\ Hala Alhodaib $\mathbb{D}^{3}$ \\ Saja A Al-Rayes $\mathbb{D}^{\prime}$ \\ Afnan Aljaffary (D) \\ Bashair AIThani $\mathbb{D D}^{4}$ \\ Heba AINujaidi $\mathbb{1}^{5}$ \\ Atheer K Al-Saif ${ }^{5}$ \\ Razaz Attar ${ }^{6}$ \\ Duaa Aljabri (D) \\ Sama'a Al-Mubarak (D) \\ Mona M Al-Juwair' \\ Sumaiah Alrawiai ${ }^{\prime}$ \\ Turki M Alanzi (D) \\ 'Health Information Management and \\ Technology Department, College of \\ Public Health, Imam Abdulrahman Bin \\ Faisal University, Dammam, Saudi Arabia; \\ ${ }^{2}$ Community College, Imam \\ Abdulrahman Bin Faisal University, \\ Dammam, Saudi Arabia; ${ }^{3}$ Department of \\ Community Health Sciences, College of \\ Applied Medical Sciences, King Saud \\ University, Riyad, Saudi Arabia; ${ }^{4}$ College \\ of Business Administration, Imam \\ Abdulrahman Bin Faisal University, \\ Dammam, Saudi Arabia; ${ }^{5}$ College of \\ Public Health, Imam Abdulrahman Bin \\ Faisal University, Dammam, Saudi Arabia; \\ ${ }^{6}$ Princess Nourah Bint Abdul Rahman \\ University, Riyad, Saudi Arabia
}

Correspondence: Turki M Alanzi Health Information Management and Technology Department, College of

Public Health, Imam Abdulrahman Bin

Faisal University, 234, King Faisal Road,

Dammam, 3I44I, Saudi Arabia

Tel +966 I3333121 I

Email talanzi@iau.edu.sa
Background: WhatsApp was the most popular messenger app used in Saudi Arabia with $71 \%$ of the total population using it in 2020 . WhatsApp is increasingly being used as a tool for mobile health (m-health) interventions; however, concerning blood donation, there is a lack of research studies on the topic.

Objective: This study aims to measure the general awareness levels of the blood donation process and assess blood donation history, the motivators and inhibitors to donating blood, and to assess the impact of WhatsApp on the blood donation process in Saudi Arabia.

Methods: In this research study, a descriptive quantitative cross-sectional analysis was adopted. A questionnaire survey was designed using Google Forms and distributed online through social media applications to collect data. All citizens aged above 18 years of age were eligible to participate in the survey. There were a total of 150 participants in the study. Results: More than $90 \%$ of participants were aware of their blood group, blood donation requirements, and causes to be deferred from the donation. Furthermore, $27 \%$ of participants donated blood because their relatives or friends needed blood, $26 \%$ donated due to human solidarity, $18 \%$ did not donate blood because of their health condition and $14 \%$ did not because of the fear of needles. About 33\% of participants relied on WhatsApp to search for blood donors, and all the requests were fulfilled with blood donors. In addition, 94\% of participants strongly believed that the WhatsApp application had a significant role in bridging the gap for blood banks' need for blood donors.

Conclusion: Social media applications such as WhatsApp can bridge the gap between blood banks, blood donors and the patients in need of blood in Saudi Arabia, where there is a shortage of blood donors.

Keywords: WhatsApp, blood donation, Saudi Arabia

\section{Introduction}

Social media plays a significant role in rapidly transforming the healthcare needs in Saudi society. The global rise in social media amounts to $9.2 \%$ annually. WhatsApp is the most popular messenger app in Saudi Arabia with 71\% of the total population using it in 2020. ${ }^{1}$ WhatsApp is increasingly being used as a tool for mobile health (m-health) interventions; however, there is a lack of research concerning blood donation and the use of messenger apps. ${ }^{2,3}$

Globally, 120 million people donate blood every year. However, this is insufficient to reach the global need because many patients are in need of a transfusion. Regular blood donations are required to ensure there is always a supply for those in need. $^{4-6}$ According to King Faisal Specialist Hospital \& Research Centre (KFSHRC), 205 donors were needed daily: 100 donors with O blood group, 50 
donors with A blood group, 50 donors with B blood group, and five donors with $\mathrm{AB}$ blood group in Saudi Arabia. ${ }^{7}$ In cooperation with the Ministry of Health, KFSHRC highlights the Wateen application as an initiative that seeks to reduce the communication gap between blood banks and donors so that donating blood becomes easier. ${ }^{7}$ There are approximately 800,000 donors registered on the Wateen application in Saudi Arabia, ${ }^{8}$ reflecting the importance of integrating mobile applications and social media in the blood donation process. The need for an effective and efficient blood donation and supply process was noticed during the COVID-19 pandemic when the blood banks were alerted due to a decrease in blood supply with a high demand for blood transfusion for patients. Many blood banks used the WhatsApp platform for blood donor mobilization campaigns to motivate donors to donate blood and meet the patients' demand for transfusion, ${ }^{9}$ and for plasma donation, which proved to be effective for generating immunity among the COVID-19 patients. $^{10-12}$

A recent study ${ }^{13}$ identified four major potential challenges with respect to blood donation during the COVID19 pandemic: blood/component shortage, donor/staff safety, consumable supply/logistics and catering to the convalescent plasma need. In addition, frequent lockdowns and curfews affected the blood collection process during the pandemic. However, various social media applications were effective in acquiring and retaining blood donors in these conditions. Social media applications such as Twitter were effective in raising blood donation requests and dissemination, reducing the gap between blood donors and the people in need. ${ }^{14,15}$ Among the various social media applications, WhatsApp was effective in managing the blood donation process. ${ }^{16}$ However, a similar study in Brazil identified there was no significant impact of WhatsApp in increasing the number of blood donors and the retention rates of existing donors. Further, the difference in the blood donors' return rates were identified in the study, suggesting specific interventions should be created according to the different stages of the donors' careers. ${ }^{2}$ Similarly, another study highlighted the need for drawing, poetry, or singing contests about donating to keep active communication with donors. ${ }^{17}$ However, blood transfusion in Saudi Arabia is essentially a hospital-based process, with the primary sources being from a combination of a growing number of voluntary non-remunerated donations and family members. ${ }^{18}$ Although there are other sources, such as regional blood banks and the Saudi Red
Crescent, there is a lack of communication between the blood banks, blood donors, hospitals and people in need. ${ }^{19}$ Due to the growing demand for blood donors, the WhatsApp platform being the most useful app among Saudi people, and the lack of research related to this area, this study aims to measure the impact of WhatsApp on the blood donation process in Saudi Arabia.

\section{Methods}

\section{Study Settings and Participants}

In this research study, a descriptive quantitative crosssectional analysis method was adopted to investigate the general awareness about the blood donation process, motivators and inhibitors of donating blood, and to measure the impact of WhatsApp on the blood donation process in Saudi Arabia. A questionnaire-based survey was conducted. The participants were provided with information about the study's purpose at the beginning of the survey. Besides, voluntary participation in the questionnaire survey was mentioned. The Institutional Review Board at Imam Abdulrahman Bin Faisal University in Dammam, Saudi Arabia, approved the ethical protocol of this research and it was conducted in accordance with the Declaration of Helsinki. Informed consent was obtained from the participants.

\section{Questionnaire Design}

The research team modified the questionnaire exported from Alanzi and Alsaeed study to reach the research objectives. ${ }^{16}$ The questionnaire survey included closedended questions with multiple choices from which the respondents were required to choose one of the available options. To ensure the participants could actively participate in the study, the questions were designed in a straightforward format to minimize errors in the findings. The questionnaire survey was translated forward and backward into the Arabic language and an academic expert reviewed it to check its clarity. The questionnaire survey was divided into three sections. The first section contained three questions about the participants' demographic data. (i) What is your gender? (male, female); (ii) What is your age group in years? $(18-28,29-39,40-50,51+)$; (iii) What is your nationality? (Saudi, Non-Saudi). The second section contained eight questions about a general awareness of blood donation, participants' history as blood donors, motivators and inhibitors to donating blood. (i) What is your blood type? (O+, O-, A+, A-, B+, 
B-, $\mathrm{AB}+, \mathrm{AB}-, \mathrm{I}$ do not know); (ii) Did you know there are requirements to become a blood donor? (yes, no); (iii) Did you know there are causes to the donor being deferred or refused from blood donation? (yes, no); (iv) Did you know the donor can donate blood for only one component such as platelets? (yes, no); (v) How often did you donate blood? (never, first time, frequently); (vi) Did you donate blood before for only one blood component? (yes, no); (vii) What is your motivation to donate blood? (relative or a friend needs blood, human solidarity, personal satisfaction of helping others, beneficial to my health, seeing or receiving an advertising campaign, friends or relatives are blood donors and they encourage me, urgent call for blood, my blood type is rare and thus always necessary); (viii) What are your inhibitors to donate? (nothing inhibits me to donate, I can't donate due to my health condition, fear of needles, I have been deferred from donation before, fear of needing blood in future, fear of infectious disease transmission, the sight of blood is unpleasant, I get nothing in return). The third section contained seven questions to measure the impact of WhatsApp on the blood donation process in Saudi Arabia. (i) Have you ever looked for a blood donor for you/relatives by WhatsApp? (yes, no); (ii) Has your blood donation request ever been fulfilled with blood donors by WhatsApp? (yes, no); (iii) How frequently do you send broadcasts or campaigning requests for blood donation on WhatsApp? (never, sometimes, often, always); (iv) How frequently do you receive broadcasts or campaigning requests for blood donation on WhatsApp? (never, sometimes, often, always); (v) What are the sources of broadcasts from which you receive the requests for blood donation through WhatsApp? (families and friends, organizations, anonymous); (vi) What is your most likely response when you receive a blood donation request on WhatsApp? (nothing, donate blood only, share it with others only, donate blood and share it with others, I would have liked to donate but I could not); (vii) Do you think there is a role for WhatsApp in bridging the gap of blood banks' need for blood donors? (yes, no, maybe). The questionnaire survey is shown in Appendix A.

A pilot study was conducted with ten reviewers, one was an academic reviewer, and the others were the authors' colleagues at Imam Abdulrahman Bin Faisal University. The results were analyzed for validity and reliability using Cronbach's alpha for all items in the questionnaire, which were identified to be greater than 0.80; thus, the questionnaire was validated. Furthermore, ethical approval was obtained from the Imam Abdulrahman Bin Faisal University.

The nine people were randomly selected.

\section{Data Collection}

The questionnaire survey was conducted online using the Google Forms platform. The participants were provided with information about the study and the measures taken, such as ensuring the anonymity, data protection, and so on. On the survey's first page, a check box was provided for participants to agree/provide their consent to participate in the survey. The questionnaire survey was distributed through social media channels including WhatsApp, Facebook, Instagram, etc. The study included citizens of Saudi Arabia, who have donated blood, and even those who have not. They were selected by using a non-probability sampling technique, specifically a convenience sample. Since the survey was sent to the public through online networks, formal sample size calculations were not possible. ${ }^{20}$ Thus, everyone who completed the questionnaire was included, as there are no exclusion criteria in the data collection process. The study was conducted for a period of four weeks from 1st June 2021 to 29th June 2021. The study had a total of 150 participants.

\section{Statistical Analysis}

A basic descriptive statistical analysis in terms of frequencies and percentages was carried out in this study using the statistical package for social sciences (SPSS) version 23.

The participants' demographic information is shown in Table 1. As seen in the table, 67 (45\%) males participated in the study, while 83 (55\%) females did. In addition, the age of the majority of the participants (78\%) was below 39 years old. Moreover, $93 \%$ of participants were Saudi.

Table I Participants' Demographic Information

\begin{tabular}{|l|c|c|c|}
\hline \multicolumn{2}{|l|}{ Demographic Characteristics } & Frequency & Percent \\
\hline Gender & Female & 83 & 55.3 \\
& Male & 67 & 44.7 \\
\hline \multirow{2}{*}{ Age group in years } & $18-28$ & 58 & 38.7 \\
& $29-39$ & 59 & 39.3 \\
& $40-50$ & 23 & 15.3 \\
& 51 and above & 10 & 6.7 \\
\hline \multirow{2}{*}{ Nationality } & Non-Saudi & 10 & 6.7 \\
& Saudi & 140 & 93.3 \\
\hline
\end{tabular}


Table 2 Participants' General Awareness About the Blood Donation Process

\begin{tabular}{|c|c|c|c|}
\hline \multicolumn{2}{|l|}{ General Awareness About the Blood Donation Process } & \multirow{2}{*}{$\begin{array}{c}\text { Frequency } \\
79\end{array}$} & \multirow{2}{*}{$\begin{array}{c}\text { Percent } \\
52.7\end{array}$} \\
\hline What is your blood type? & $\mathrm{O}+$ & & \\
\hline & $A+$ & 36 & 24.0 \\
\hline & $\mathrm{B}+$ & 10 & 6.7 \\
\hline & $A B+$ & 1 & 0.7 \\
\hline & O- & 14 & 9.3 \\
\hline & A- & 3 & 2.0 \\
\hline & I do not know & 7 & 4.7 \\
\hline \multirow[t]{2}{*}{ Did you know there are requirements to become a blood donor? } & Yes & $|4|$ & 94.0 \\
\hline & No & 9 & 6.0 \\
\hline \multirow[t]{2}{*}{ Did you know there are causes to the donor being deferred or refused from blood donation? } & Yes & $|4|$ & 94.0 \\
\hline & No & 9 & 6.0 \\
\hline \multirow[t]{2}{*}{ Did you know the donor can donate blood for only one component, such as platelets? } & Yes & 88 & 58.7 \\
\hline & No & 62 & 41.3 \\
\hline
\end{tabular}

Furthermore, Table 2 shows the participants' general awareness about the blood donation process. The majority of participants knew their blood group; half of them were $\mathrm{O}+$ blood group (see Figure 1), while only $5 \%$ did not know their blood group. Also, 94\% of participants were aware of the requirements to become a blood donor, and that there were causes for donors to be deferred or refused from blood donation. However, the awareness level dropped to $59 \%$ when the participants were asked if they could donate blood for only one component such as platelets.

Table 3 shows that $44.7 \%$ of the participants had previously donated blood, while $55.5 \%$ noted that they had never participated in a blood donation process. Of the participants, $13.3 \%$ had donated blood for only one blood component, such as platelets. With respect to the motivations

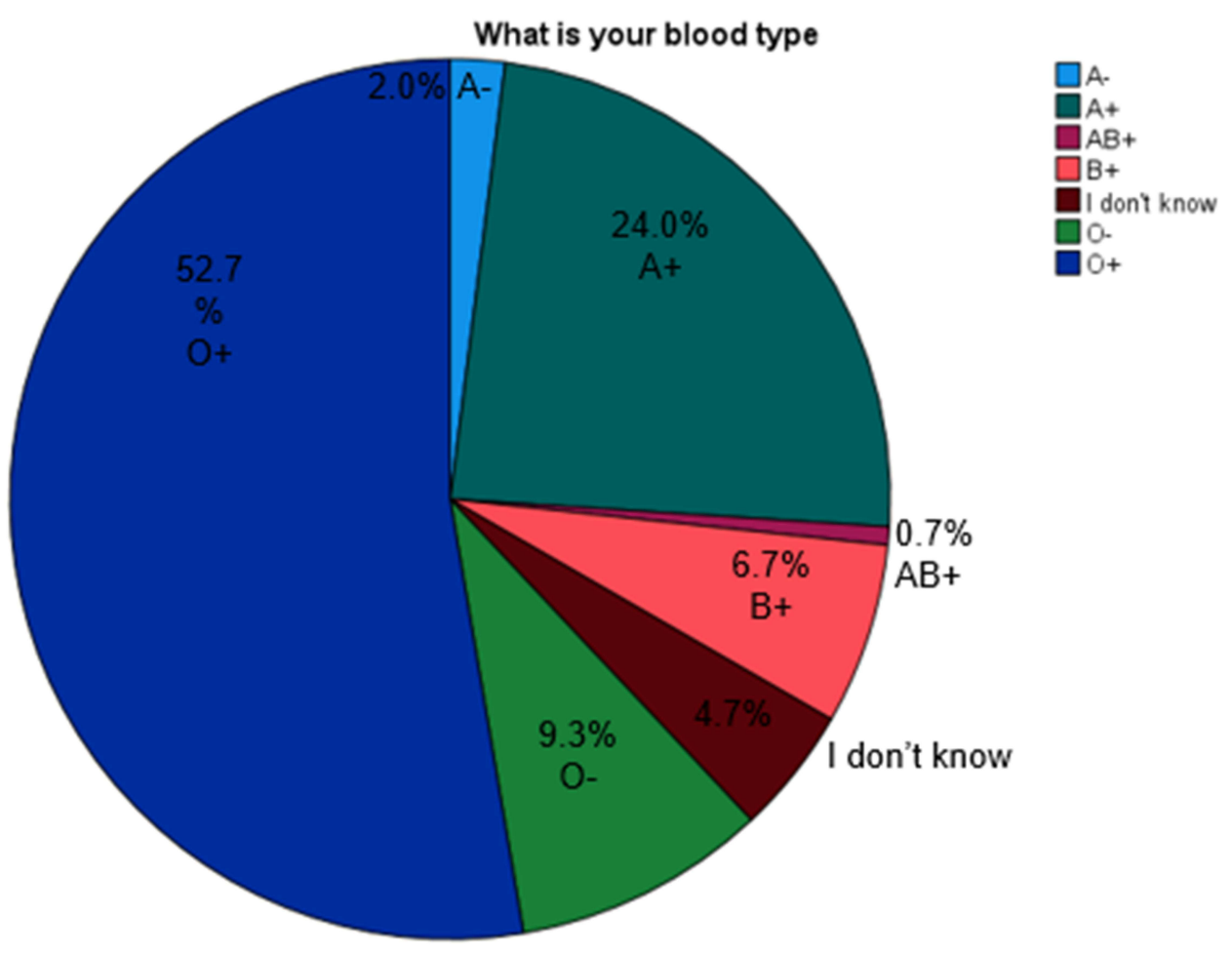

Figure I The variation of blood groups among the participants. 
Table 3 Blood Donation History and Motivators and Inhibitors for Blood Donation

\begin{tabular}{|c|c|c|c|}
\hline \multicolumn{2}{|c|}{ Blood Donation History and Motivators and Inhibitors for Blood Donation } & \multirow{2}{*}{$\frac{\text { Frequency }}{83}$} & \multirow{2}{*}{$\frac{\text { Percent }}{55.3}$} \\
\hline How frequent did you donate blood? & Never & & \\
\hline & First time & 49 & 32.7 \\
\hline & Frequently & 18 & 12 \\
\hline \multirow{2}{*}{$\begin{array}{l}\text { Did you donate blood before for only one blood } \\
\text { component? }\end{array}$} & No & 130 & 86.7 \\
\hline & Yes & 20 & 13.3 \\
\hline \multirow[t]{7}{*}{ What is your motivation to donate blood? } & Relative or a friend needs blood & 41 & 27.3 \\
\hline & Human solidarity & 39 & 26.0 \\
\hline & Personal satisfaction of helping others & 34 & 22.7 \\
\hline & Beneficial to my health & 23 & 15.3 \\
\hline & Seeing or receiving an advertising campaign & 5 & 3.3 \\
\hline & Friends or relatives are blood donors and they encouraged & 4 & 2.7 \\
\hline & $\begin{array}{l}\text { me } \\
\text { Urgent call for blood }\end{array}$ & 4 & 2.7 \\
\hline \multirow[t]{8}{*}{ What are your inhibitors to donate? } & Nothing inhibits me to donate & 68 & 45.3 \\
\hline & I can't donate due to my health condition & 27 & 18.0 \\
\hline & Fear of needles & 21 & 14.0 \\
\hline & I have been deferred from donation before & 13 & 8.7 \\
\hline & Fear of needing blood in the future & 10 & 6.7 \\
\hline & Fear of infectious disease transmission & 6 & 4.0 \\
\hline & The sight of blood is unpleasant & 4 & 2.7 \\
\hline & I get nothing in return & I & 0.7 \\
\hline
\end{tabular}

Table 4 The Impact of the WhatsApp Platform on the Blood Donation Process

\begin{tabular}{|c|c|c|c|}
\hline \multicolumn{2}{|l|}{ The Impact of the WhatsApp Platform in the Blood Donation Process } & \multirow{3}{*}{$\begin{array}{c}\text { Frequency } \\
100 \\
50\end{array}$} & \multirow{3}{*}{$\begin{array}{c}\text { Percent } \\
66.7 \\
33.3\end{array}$} \\
\hline Have you ever looked for a blood donor for you/relatives through WhatsApp? & No & & \\
\hline & Yes & & \\
\hline \multirow[t]{2}{*}{ Has your blood donation request ever been fulfilled with blood donors by WhatsApp? } & No & 101 & 67.3 \\
\hline & Yes & 49 & 32.7 \\
\hline \multirow{4}{*}{$\begin{array}{l}\text { How frequently do you send broadcasts or campaigning requests for blood donation } \\
\text { on WhatsApp? }\end{array}$} & Never & 108 & 72.0 \\
\hline & Sometimes & 36 & 24.0 \\
\hline & Often & 5 & 3.3 \\
\hline & Always & I & 0.7 \\
\hline \multirow{4}{*}{$\begin{array}{l}\text { How frequently do you receive broadcasts or campaigning requests for blood donation } \\
\text { on WhatsApp? }\end{array}$} & Never & 48 & 32.0 \\
\hline & Sometimes & 54 & 36.0 \\
\hline & Often & 26 & 17.3 \\
\hline & Always & 22 & 14.7 \\
\hline \multirow{3}{*}{$\begin{array}{l}\text { What are sources of broadcasts from which you receive the requests for blood } \\
\text { donation through WhatsApp? }\end{array}$} & Families and Friends & 107 & 71.3 \\
\hline & Organizations & 22 & 14.7 \\
\hline & Anonymous & 21 & 14.0 \\
\hline \multirow[t]{5}{*}{$\begin{array}{l}\text { What is your most likely response when you receive the blood donation requests on } \\
\text { WhatsApp? }\end{array}$} & $\begin{array}{l}\text { I would like to donate but } \\
\qquad \text { I cannot }\end{array}$ & 40 & 26.7 \\
\hline & Share it with others only & 37 & 24.7 \\
\hline & Donate blood only & 13 & 8.7 \\
\hline & $\begin{array}{c}\text { Donate blood and share it } \\
\text { with others }\end{array}$ & 31 & 20.7 \\
\hline & Nothing & 29 & 19.3 \\
\hline
\end{tabular}


behind donating blood, $27 \%$ of the subjects stated they donated blood due to their relatives or friends needing blood. This was followed by $26 \%$ of the participants who noted they only donated for a sense of human solidarity, and $23 \%$ indicated they donated blood to be satisfied when helping others. The remaining respondents donated blood for other reasons, as shown in Table 3. Related to the inhibitors to donating, $18 \%$ of the respondents stated they did not donate blood because of their health condition, and $1 \%$ pointed out they did not engage in the process because they did not get anything in return. Further, $14 \%$ noted they did not participate because of their fear of needles, while $3 \%$ found the sight of blood unpleasant.

Another relevant part of the investigation was to assess the impact of WhatsApp platform on the blood donation process. Table 4 shows that $33 \%$ of participants looked for blood donation opportunities by using WhatsApp, and all the requests for blood donation via WhatsApp were fulfilled with blood donors. Almost $28 \%$ of subjects, ranging from sometimes to always, participated in sending broadcasts or campaigning for requests for blood donation on WhatsApp, while $72 \%$ of participants responded they never participated in sending broadcasts or campaigning requests for blood donation on WhatsApp. Further, 32\% of participants stated they never received broadcasts or campaigning requests for blood donation on WhatsApp, while others, ranging from sometimes to always, received broadcasts or campaigning requests for blood donation on WhatsApp. For the broadcasts of blood donation requests that participants received through WhatsApp, $71 \%$ were from families and friends, while $15 \%$ of participants received broadcasts about blood donation requests from organizations and others received broadcasts about blood donation requests from anonymous sources. Participants' response to the broadcasts requesting blood donors was measured and $27 \%$ of them said they wanted to donate but couldn't, while $25 \%$ shared the broadcast with others only, $21 \%$ donated blood and shared broadcast, $9 \%$ donate blood only, and $19 \%$ of participant did nothing.

Finally, as shown in Figure 2, 94\% of participants believed there was a role for WhatsApp in bridging the gap of blood banks' need for blood donors and only $6 \%$ thought there was no role of WhatsApp in bridging this gap.

\section{Discussion}

Based on the analyzed results, it is evident that WhatsApp plays a significant role in bridging the gap for blood banks' need for blood donors by using broadcasts, posts and campaigns in Saudi Arabia. This evidence is confirmed considering the information provided in Table 4, which shows that most of the participants in Saudi Arabia, who have sent broadcasts requesting blood donation messages through WhatsApp have had their requests fulfilled. This finding suggests that WhatsApp can promote blood donation programs to a high proportion of Saudi citizens. Moreover, this finding is supported by Alanzi and Alsaeed ${ }^{16}$ and Waheed et al's ${ }^{9}$ studies where they found WhatsApp was the most

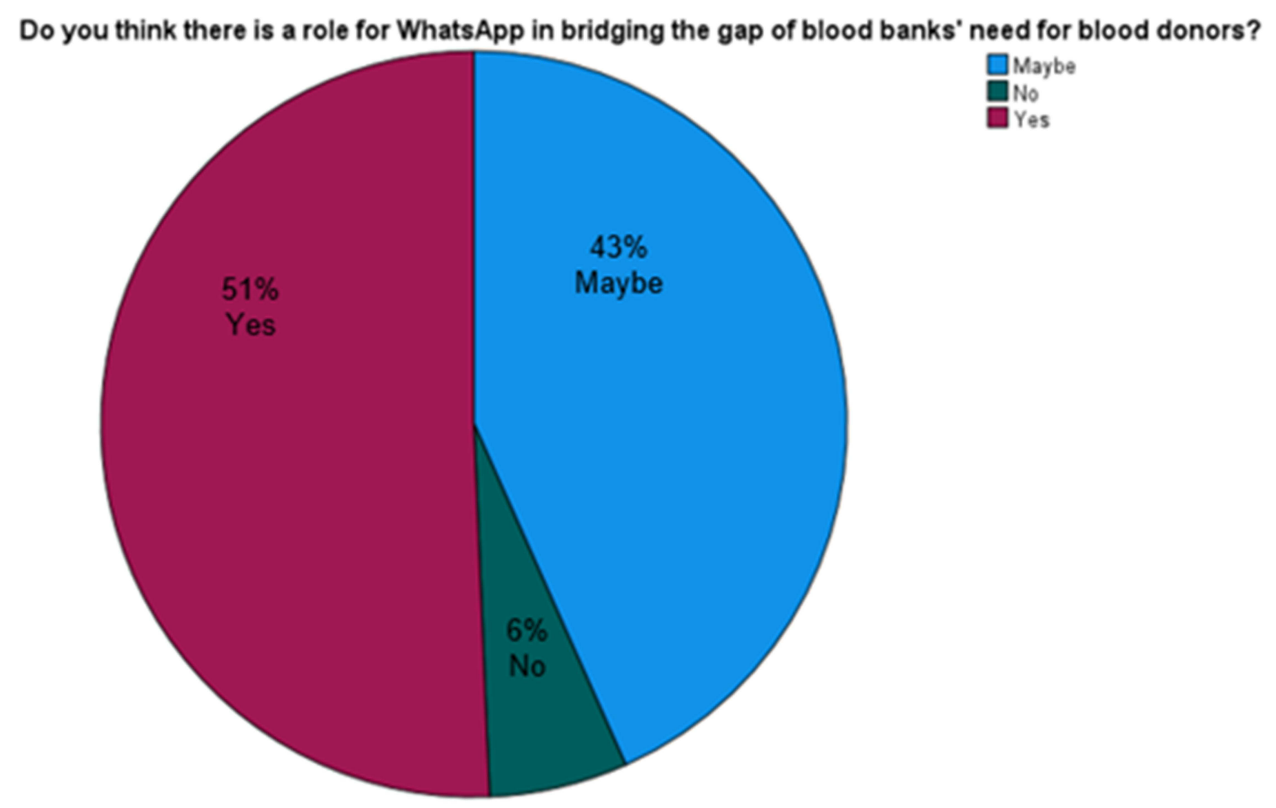

Figure 2 The impact of WhatsApp in bridging the gap between blood banks and blood donors in the participants' view. 
useful social media tool in receiving the blood donation requests. Also, Table 4 shows that most of the sources of broadcasts and posts received through WhatsApp were from friends and family. Similar to what Alanzi and Alsaeed found in their study, friends and family were the primary source of broadcasts about blood donation. ${ }^{16}$ In the same way, almost a half of the participants expressed they shared the broadcasts about the need for blood donors, while onethird of participants donated blood in response to the broadcasts received through the WhatsApp platform.

Furthermore, the participants expressed their opinion about their motivations and inhibitor factors from blood donation. In this sense, and according to Table 3 , half of the participants considered that the motivation to donate blood was that a relative or friend needed blood, $26 \%$ felt human solidarity by donating, and $18 \%$ said they did not donate blood and were inhibited due to their health conditions.

As shown in Table 2, most participants were aware of the blood donation requirements and the causes for being deferred from donating. Nevertheless, around $60 \%$ of participants were not aware of the ability to donate only one component of blood. When the awareness was enhanced, the people who feared needing blood in the future donated blood for only one component, such as platelets, which have a life span of about eight days. ${ }^{21}$

Implementing an effective blood donation program in Saudi Arabia using WhatsApp platforms is possible. Alanzi and Alsaeed study supports these suggestions because their research outcome indicated that WhatsApp's popularity was essential and critical in promoting blood donation in Saudi Arabia. ${ }^{16}$ Besides, the program would be more successful if it allowed the families and friends to share information about blood donation based on what is approached in our study, namely that families and friends were the major sources of broadcasts about blood donation. Moreover, the Saudi people's awareness of blood donation through social media, TV advertisements and campaigns should be increased.

This research's main limitations were limited resources, a small sample size, and short surveying time. Firstly, the sample identified in this study is low (150 participants); as a result, generalizing the results must be done with care. Secondly, while there are other popular social media applications, only WhatsApp was considered for the analysis. This study has both practical and theoretical implications. Firstly, there is a lack of research in Saudi Arabia on the use of social media applications in the blood donation process. Considering this gap, this study contributes to the existing literature. In addition, hospitals and healthcare administrative agencies can use this study's findings to understand the user's reliance on and behaviors surrounding using social media platforms for the blood donation process. Therefore, integrating these applications with hospitals, blood banks and donors could help improve the blood donation and management process.

Consequently, future studies will be addressed to avoid these limitations and evaluate, using statistical techniques, whether WhatsApp effectively improves the blood donation process in Saudi Arabia if the blood banks use it and promote voluntary non-remunerated blood donation, a family member's donation, or both contributions. It would also be interesting to compare a blood donor's behavioral intention before and after receiving messages on WhatsApp and between those who donate and those who do not.

\section{Conclusion}

This study's outcomes indicated that the Saudi people were aware of the blood donation process and half of them donated blood and were motivated to do so by a relative or a friend who needed blood and human solidarity, while those who did not donate blood were inhibited by their health condition. The WhatsApp platform announced the need for blood donors and the needs were fulfilled after announcements. Meaning, WhatsApp can bridge the communication gap between blood banks and the patients in need in Saudi Arabia, where there is a shortage of blood donors. Furthermore, as the number of users on WhatsApp is considerably high, social media applications can be integrated into eHealth platforms to streamline the resources and ensure the availability and accessibility of blood among the hospitals and the patients, which can improve operational efficiency. Overall, social media applications such as WhatsApp have huge potential to improve healthcare operations, which need to be explored more in the future research studies.

\section{Acknowledgment}

Fahad Alanezi advises their new affiliation is with the College of Business Administration, Imam Abdulrahman Bin Faisal University, Dammam, Saudi Arabia.

\section{Disclosure}

The authors report no conflicts of interest in this work. 


\section{Reference}

1. Saudi Arabia social media statistics 2020 (Infographics) - GMI Blog [Internet]; [cited December 31, 2020]. Available from: https://www. globalmediainsight.com/blog/saudi-arabia-social-media-statistics/. Accessed November 6, 2021.

2. Rodrigues Lucena TF, Queiroz Negri L, Marcon D, Yamaguchi MU. Is WhatsApp effective at increasing the return rate of blood donors? Telemed e Health. 2020;26(3):304-309. doi:10.1089/tmj.2019.0024

3. Healy J, Murphy M. Social marketing: the lifeblood of blood donation? In: The Customer is NOT Always Right? Marketing Orientations in a Dynamic Business World; 2017:811.

4. Blood transfusion safety [Internet]; [cited December 31, 2020]. Available from: https://www.who.int/westernpacific/health-topics/ blood-transfusion-safety. Accessed November 6, 2021.

5. Ali R, Hafez T, Ali A, Abd-Alsabour N. Blood bag: a web application to manage all blood donation and transfusion processes. 2017 International Conference on Wireless Communications, Signal Processing and Networking (WiSPNET); 2017. doi:10.1109/ WiSPNET.2017.8300136.

6. Asamoah-Akuoko L, Hassall O, Bates I, Ullum H. Blood donors' perceptions, motivators and deterrents in Sub-Saharan Africa a scoping review of evidence. $B r \quad J$ Haematol. 2017;177 (6):864-877. doi:10.1111/bjh.14588

7. Blood donation [Internet]. King Faisal Specialist Hospital \& Research Centre; [cited December 31, 2020]. Available from: https://www.kfshrc.edu.sa//en/home/giving/blood. Accessed November 6, 2021.

8. Wateen. Wateen app [Internet]; [cited December 31, 2020]. Available from: https://www.wateenapp.org/\#download. Accessed November 6, 2021. Sindhi.

9. Waheed U, Wazeer A, Saba N, Qasim Z. Effectiveness of WhatsApp for blood donor mobilization campaigns during COVID-19 pandemic. ISBT Sci Ser. 2020;15:378-380. doi:10.1111/voxs. 12572

10. Klassen S, Senefeld J, Johnson P, et al. The effect of convalescent plasma therapy on mortality among patients with COVID-19: systematic review and meta-analysis. Mayo Clin Proc. 2021;96 (5):1262-1275. doi:10.1016/j.mayocp.2021.02.008

11. Shi H, Zhou C, He P, et al. Successful treatment with plasma exchange followed by intravenous immunoglobulin in a critically ill patient with COVID-19. Int J Antimicrob Agents. 2020;56(2):105974. doi:10.1016/j.ijantimicag.2020.105974
12. Ye M, Fu D, Ren Y, et al. Treatment with convalescent plasma for COVID-19 patients in Wuhan, China. J Med Virol. 2020;92 (10):1890-1901. doi:10.1002/jmv.25882

13. Arcot PJ, Kumar K, Mukhopadhyay T, Subramanian A. Potential challenges faced by blood bank services during COVID-19 pandemic and their mitigative measures: the Indian scenario. Transfus Apher Sci. 2020;59(5):102877. doi:10.1016/j.transci.2020.102877

14. Abbasi R, Maqbool O, Mushtaq M, et al. Saving lives using social media: analysis of the role of twitter for personal blood donation requests and dissemination. Telemat Inform. 2018;35(4):892-912. doi:10.1016/j.tele.2017.01.010

15. Mathur P, Ayyar M, Chopra S, Shahid S, Mehnaz L, Shah RR. Identification of emergency blood donation request on Twitter. Proceedings of the 3rd Social Media Mining for Health Applications (SMM4H) Workshop \& Shared Task. Brussels, Belgium; 2018:27-31.

16. Alanzi T, Alsaeed B. Use of social media in the blood donation process in Saudi Arabia. $J$ Blood Med. 2019;10:417-423. doi:10.2147/JBM.S217950

17. Khomenko LM. Social marketing communications for blood donors retention. Socio-humanitarian aspects of modern society development: Proceedings of the eighth All-Ukrainian scientific conference of students, graduate students, teachers and staff. Sumy State University; 2020:312-315.

18. Elsafi S. Demographical pattern of blood donors and pre-donation deferral causes in Dhahran, Saudi Arabia. $J$ Blood Med. 2020;11:243-249. doi:10.2147/JBM.S254168

19. Otifi H, Asiri M, Ahmad M, et al. Measuring public awareness about blood donation in Assir, South-Western Saudi Arabia. Transfus Clin Biol. 2020;27(3):122-127. doi:10.1016/j.tracli.2020.06.005

20. Al-rayes SA, Aldossary $\mathrm{H}$, Aldoukhi E, Alahmedalyousif Z, Aldawood G, Alumran A. The awareness and utilization of 937-telephone health services in Saudi Arabia: cross-sectional survey study. Inform Med Unlocked. 2020;20:100393. doi:10.1016/j. imu.2020.100393

21. Thrombopoietin and platelet production in chronic immune thrombocytopenia- ClinicalKey [Internet]; [cited December 31, 2020]. Available from: https://www-clinicalkey-com.library.iau.edu. sa/\#!/content/playContent/1-s2.0-S0889858809001725?returnurl= null\&referrer=null. Accessed November 6, 2021.
Journal of Blood Medicine

\section{Publish your work in this journal}

The Journal of Blood Medicine is an international, peer-reviewed, open access, online journal publishing laboratory, experimental and clinical aspects of all aspect pertaining to blood based medicine including but not limited to: Transfusion Medicine; Blood collection, Donor issues, Transmittable diseases, and Blood banking logistics; Immunohematology; Artificial and alternative blood based therapeutics; Hematology; Biotechnology/nanotechnology of blood related medicine; Legal aspects of blood medicine; Historical perspectives. The manuscript management system is completely online and includes a very quick and fair peer-review system. Visit http://www.dovepress.com/testimonials.php to read real quotes from published authors. 